\title{
EXPERIMENTAL INVESTIGATION OF FLAT PLATE COLLECTOR SYSTEM PERFORMANCE USING GALVANIZED STEEL ABSORBER IN DUHOK CLIMATE
}

\author{
MAHIR ISMAEl AHMED* and OMAR MOHAMMED Ali ${ }^{* *}$ \\ *Dept. of Energy Engineering, Technical College of Engineering, Duhok Polytechnic, \\ Kurdistan Region-Iraq. \\ ** Dept. of mechanical engineering, college of engineering, university of Zakho, \\ Kurdistan Region-Iraq.
}

(Received: April 16, 2019; Accepted for Publication: September 18, 2019)

\begin{abstract}
The present work includes the design and fabrication of the flat plate solar collector system. The performance of the system is investigated experimentally using galvanized steel sheet with $0.4 \mathrm{~mm}$ thickness as an absorber plate with black coating, the collector area is $0.54 \mathrm{~m}^{2}$. The test is conducted in Iraq, Kurdistan region, Duhok city on January 10, 2019, for five hours. The collector efficiency is satisfactory as compared with previous study. The useful heat gain and efficiency of collector have been calculated from the collected data. The results display that there are many factors and parameters such as wind speed, collector heat removal factor, heat losses coefficient and transmission-absorption product affected on collector efficiency.
\end{abstract}

KEYWORDS: Flat plate collector, Galvanized steel, absorber plate, thermal efficiency

\section{INTRODUCTION}

$\mathbf{T}$ he solar energy is one type of renewable energy that used as an alternative of fossil fuel. The conversion of solar radiation into heat is one of the simplest application of solar energy. Nowadays, the installed solar collectors are spread around the world and reach to about 30 million squares meters (Khedher, 2018).

A solar collector is one kind of heat exchanger which is used to transform the solar energy into heat. In the solar collector, the working fluid absorbs the energy from the sun as a source of radiation energy (John A. Duffie, 2013). Also, the easy maintenance and operation of a solar heating system lead to employment it in industrial and domestic sectors (Jalaluddin, Arif, \& Tarakka, 2016).

There are two main components of solar water system that used for heating the buildings which are solar collectors and storage tank. The major system component is the solar collector which is used to heat the fluid by absorbing the radiation from the sun and transfer it into heat in absorber plate then transfer the absorbed heat to working fluid.
The passive and active systems are two types of solar water heating system used for circulating the fluid inside the system. In the passive system, the fluid movement depends on gravity while in an active system, the pump is used to move the working fluid (Dabhane \& Adhau, 2014).

Flat plate collector is one of the nonconcentrating types that used the solar heating system for space and homes. The flat plate collectors consist of frame, insulated box to reduce the heat loss, dark color absorber plate to absorb the solar radiation and cover either glass or plastic for transmitting the radiation. In flat plate collectors, it can heat up the fluid up to 80 ${ }^{\circ} \mathrm{C}$.

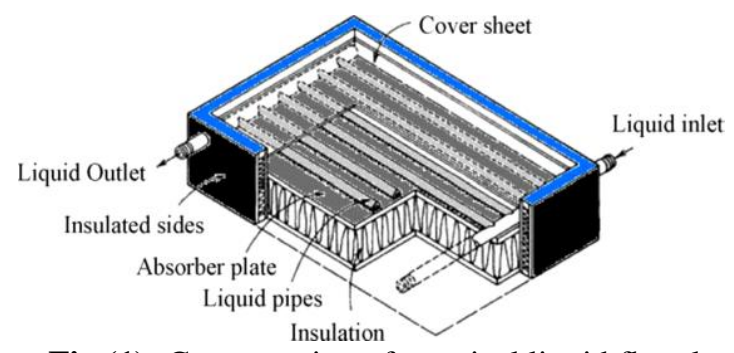

Fig.(1): Cross-section of a typical liquid flat plate collector

mahir.ahmed@dpu.edu.krd, omar.ali@uoz.edu.krd 
(Bakari, Minja, \& Njau, 2014) experimentally investigated the effect of glass thickness on the performance of flat plate collector, and designed four modules with different thicknesses and found out that $4 \mathrm{~mm}$ thickness glass had higher performance than 3, 5 , and $6 \mathrm{~mm}$ thickness. (Ihaddadene, Ihaddadene, \& Mahdi, 2014) investigated experimentally the effect of the number of covered glass on the performance of the collector, they found that the heat absorption by working fluid is decreased by increasing the number of covered glass. (Dabhane \& Adhau, 2014) studied experimentally the heat removal factor of the solar collector for high radiation level which is higher than those for low radiation level, and the efficiency of the collector for highlevel radiation is higher than those for low radiation level. (Ekramian, Etemad, \& Haghshenasfard, 2014) study the effect of crosssectional geometry on the performance of flat plate solar collector, and it observed that the circular cross-section is most efficient than other geometrics. (Guf'ta \& P., 1989), studies a gap spacing between the absorber and cover glazing in flat plate solar collectors, and display that the $50 \mathrm{~mm}$ air gap more efficient than 25 and 150 mm spacing.
The aim of the present work is an experimental investigation to test the performance of flat plate solar collector system using galvanized steel as an absorbent plate in the Duhok climate on the day January 10, 2019, for five hours. The study includes the investigation of the temperatures for different parts of the system, useful energy and thermal efficiency of the solar collector. The advantages of this work are heating the water using solar energy by utilizing the galvanized steel plate as an absorber plate which is available and unexpansive in the local markets. Also, this is the first investigation on this expermintal study on Duhok climate.

\section{EXPERIMENTAL SETUP}

The flat plate water heating system has been designed and built for this study. The system is carried out in Duhok city $\left(36^{\circ} 51^{\prime} \mathrm{N} 42^{\circ} 58^{\prime} \mathrm{E}\right)$. The solar collector is tilted with an optimum angle of $34.5^{\circ}$ with horizontal (Khadim, Mahdi, \& Ubaid, 2014). The collector consists of an absorber plate with $4 \mathrm{~mm}$ thick galvanized steel coated by black oil paint as shown in figure 2 .

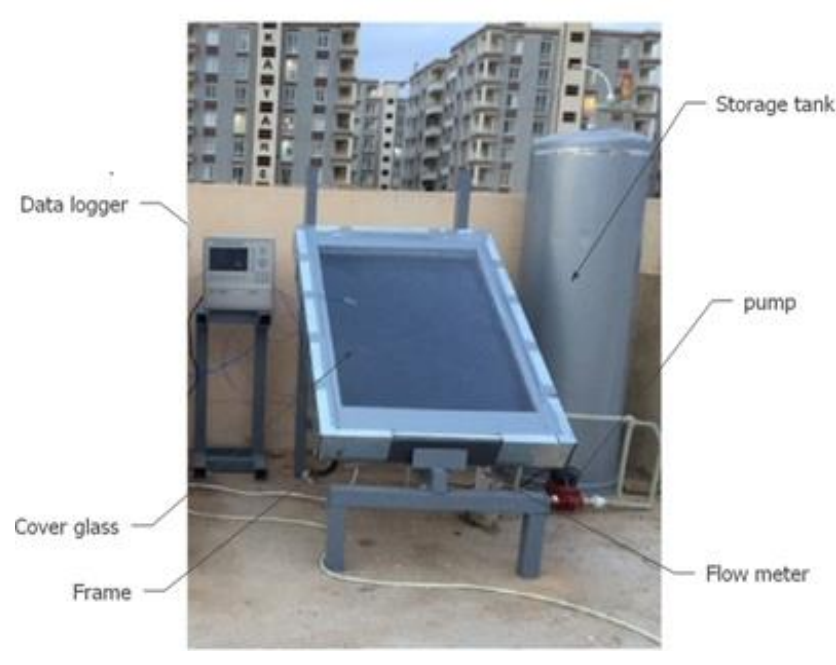

Figure (2) solar water heating system 


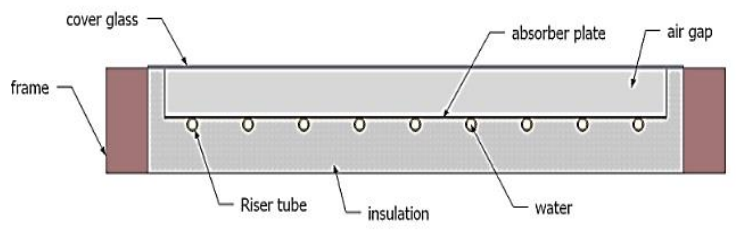

Fig. (3): collector cross section

In this study the used system is an active system by using water circulation pump with a constant flow rate of 2 liters $/ \mathrm{min}$, the system capacity is 106 liters, also the NAPUI 16 channel data logger have been used to collect and record the data. K-type thermocouple, pyranometer, and anemometer are used in this study as shown in figure 3 . The collector characteristics are shown in table 1.

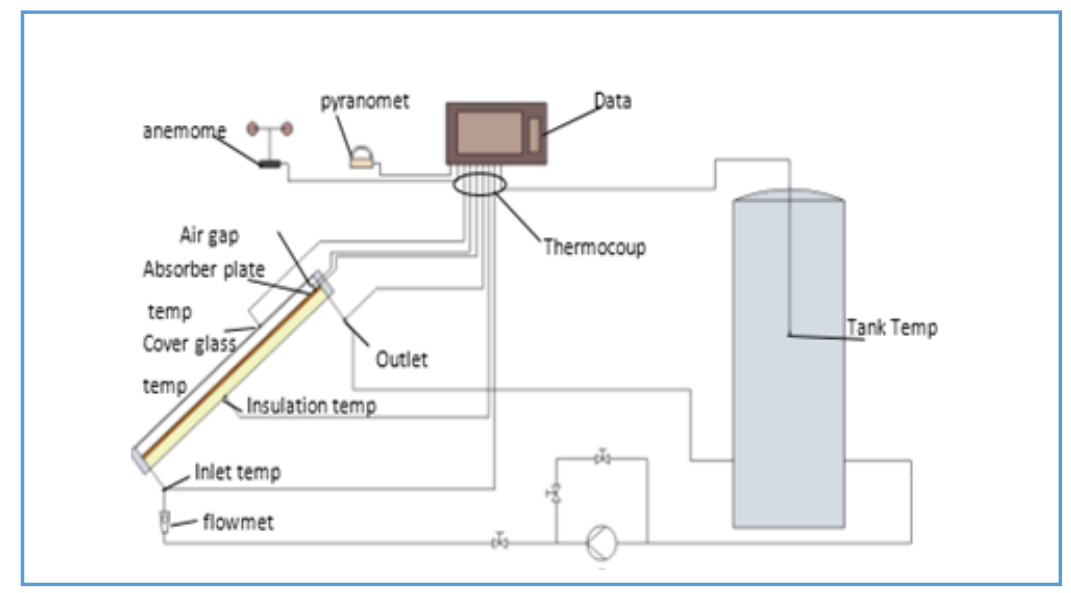

Fig. (4): schematic diagram of SWHS

Table (1): characteristics of the collector

\begin{tabular}{ll}
\hline Item & Characteristic \\
\hline Collector dimension & $1.04 \mathrm{~m} \times 0.74 \mathrm{~m}$ \\
\hline $\begin{array}{l}\text { Effective collector } \\
\text { dimension }\end{array}$ & $0.9 \mathrm{~m} \times 0.6 \mathrm{~m}$ \\
\hline Raiser tube & Copper tube, \\
& No. of tube 9 \\
& Length $0.86 \mathrm{~m}$ \\
& Diameter $12.7 \mathrm{~mm}$ \\
& \\
\hline Absorber plate & Galvanized steel \\
& The thickness of $0.4 \mathrm{~mm}$ \\
\hline Cover glass & thickness $4 \mathrm{~mm}$ \\
& transmission 0.88 \\
\hline Insulation & Thermal conductivity, \\
& $0.021 \mathrm{w} / \mathrm{m} 2$ \\
\hline Air gap & The thickness of $4.1 \mathrm{~cm}$ \\
\hline & + \\
\hline
\end{tabular}




\section{MATHEMATICAL MODEL}

To determine the flow type of the water in the pipe (laminar or turbulent). The Reynolds number is calculated as:

$$
R e=\frac{\rho V D}{\mu}
$$

where $\rho$ is the water density, $\mathrm{V}$ is the average velocity in the pipe, $\mathrm{D}$ is the pipe diameter and $\mu$ is the dynamic viscosity of the flowing water.

From the calculation, the Reynolds number between 443 and 560. This means the flow is laminar.

The amount of received solar radiation by the collector is

$$
Q_{i}=I . A
$$

where $\mathrm{A}$ is the surface area of collector, $\mathrm{m}^{2}$.

I is the solar radiation intensity, $\mathrm{W} / \mathrm{m}^{2}$.

The transparent solar ray through the glass is the transmission $\tau$ and absorbed solar ray by absorber plate is the absorption $\alpha$. The product of two parameters is called effective transmittance-absorption coefficient. Thus,

$$
Q_{i}=I(\tau \alpha) \cdot A
$$

$\tau$ and $\alpha$ are transmittance and absorption of glazing and absorber plate.

The heat loss rate $\left(Q_{O}\right)$ is depend on the overall heat loss coefficient $\left(U_{L}\right)$ and the temperature of the collector. Then,

$$
Q_{o}=U_{L} A\left(T_{c}-T_{a}\right)
$$

The overall heat loss coefficient is equal to (Dabhane \& Adhau, 2014):

$$
U_{L}=U_{t}+U_{b}+U_{e}
$$

The top heat loss coefficient $\left(U_{t}\right)$ is given by (John A. Duffie, 2013):

$$
\begin{gathered}
U_{t}=\left(\frac{N}{\frac{C}{T_{P m}}\left[\frac{\left(T_{P m}-T_{a}\right)}{(N+f)}\right]^{e}}+\frac{1}{h_{w}}\right)^{-1}+ \\
\frac{\sigma\left(T_{P m}+T_{a}\right)\left(T_{P m}{ }^{2}+T_{a}^{2}\right)}{\frac{1}{\varepsilon_{P}+0.00591 N h_{w}}+\frac{2 N+f-1+0.133 \varepsilon_{P}}{\varepsilon_{g}}-N}
\end{gathered}
$$

Where:

$N$ is the number of glass covers

$$
\begin{aligned}
f= & \left(1+0.089 h_{w}-0.1166 h_{w} \varepsilon_{P}\right)(1+ \\
& 0.07866 N) \\
C= & 52091-
\end{aligned}
$$$$
\left.0.000051 \beta^{2}\right) \quad \text { for } 0^{\circ}<\beta<70^{\circ} \text {; }
$$$$
\text { for } 70^{\circ}<\beta<90^{\circ} \text {, use } \beta=70^{\circ}
$$$$
\left.e=0.43091-100 / T_{P m}\right)
$$

$\beta$ is collector tilt (deg)

$\varepsilon_{g}$ is emittance of glass (0.88)
$\varepsilon_{P}$ is emittance plate

$T_{a}$ is ambient temperature (K)

$T_{P m}$ is mean plate temperature $(\mathrm{K})$

$\left.{ }^{\circ} \mathrm{C}\right)$

$h_{w}$ is wind heat transfer coefficient $\left(\mathrm{W} / \mathrm{m}^{2}\right.$

The $K_{i}$ and $L_{i}$ are the insulation thermal conductivity and thickness respectively, $A_{e}$ is edge area

$$
\begin{array}{r}
U_{b}=\frac{K_{i}}{L_{i}} \\
U_{e}=U_{b}\left(\frac{A_{e}}{A_{C}}\right)
\end{array}
$$

where $U_{b}$ and $U_{e}$ are bottom loss coefficient and edge loss coefficient

The extracted useful energy rate $\left(Q_{u}\right)$ by the solar collector can be expressed by:

$$
\dot{Q}_{u}=I \tau \alpha \cdot A-U_{L} A\left(T_{i}-T_{a}\right)
$$

The carried-out amount of heat in the fluid in the collector also can be measured as the useful energy rate, therefore:

$$
\dot{Q}_{u}=\dot{m} C_{P}\left(T_{o}-T_{i}\right)
$$

The collector heat removal factor defines as the ratio of actual energy gain by the collector to the useful gain if the whole surface of the collector is at the same temperature of inlet water. Thus,

$$
F_{R}=\frac{\dot{m} C_{p}}{A \cdot U_{L}}\left[1-\exp \left(-\frac{A \cdot U_{L} F^{\prime}}{m \cdot C_{p}}\right)\right]
$$

where $F^{\prime}$ is collector efficiency factor.

The actual useful energy gain $\left(Q_{u}\right)$ can be obtained by multiplying the heat removal factor of the cotlector by maximum possible useful energy gain by collector which is obtained when the temperature of the inlet water is equal to the collector temperature. It is generally known as the "Hottel- Whillier-Bliss equation".

$$
\dot{Q}_{u}=F_{R} A\left[I \tau \alpha-U_{L}\left(T_{i}-T_{a}\right)\right]
$$

The efficiency of the flat plate collector $(\eta)$ is a ratio of useful energy gain to incident solar energy over a specific time of period. (John A. Duffie, 2013)

$$
\eta=\frac{\int \dot{Q}_{u} d t}{A \int I d t}
$$

If conditions are constant over a time period, the thermal efficiency of the collector reduced to:

$$
\begin{gathered}
\eta=\frac{\dot{Q}_{u}}{A I} \\
\eta=\frac{F_{R} A\left[I \tau \alpha-U_{L}\left(T_{i}-T_{a}\right)\right]}{A I}
\end{gathered}
$$

To calculate more accurate calculation for thermal efficiency the experimental uncertainty $\left(\omega_{\eta}\right)$ have been used (Holman, 2001), then:

mahir.ahmed@dpu.edu.krd, 


$$
\begin{aligned}
\eta=f\left(I, T_{i}, T_{a}\right) & \\
\omega_{\eta}=\left\{\left(\frac{\partial \eta}{\partial I} \omega_{I}\right)^{2}\right. & +\left(\frac{\partial \eta}{\partial T_{i}} \omega_{T_{i}}\right)^{2} \\
& \left.+\left(\frac{\partial \eta}{\partial T_{a}} \omega_{T_{a}}\right)^{2}\right\}^{0.5}
\end{aligned}
$$

When $\omega_{T_{i}}, \omega_{T_{a}}$ are temperature uncertainty, $\omega_{I}$ is pyranometer uncertainty.

If $\omega_{T_{i}}=\omega_{T_{a}}= \pm 1^{\circ} \mathrm{C}, \omega_{I}= \pm 1 \mathrm{~W} / \mathrm{m}^{2}$

Then the efficiency uncertainty is $\omega_{\eta}= \pm 3.01 \%$

\section{RESULTS AND DISCUSSION}

The solar water heating system using flat plate solar collector is investigated experimentally for a particular winter day, January 10, 2019, within five hours with average ambient temperature is $\left(8.7{ }^{\circ} \mathrm{C}\right)$. Figures 5 to 8 represent the results of the present study. The efficiency of the collector for present study is compared with the efficiency of a theoretical study in (Hamood, Salim, \& Abdulrazzaq, 2014) in which the plain carbon steel as absorber plate is used at Mosul city weather conditions as shown in figure (5). It can be noticed that the efficiency curve of both studies have very good agreements. The little difference in the effeciencies of two studies due to different collectors size, material and weather conditions. The figure display that the efficiency of collectors decrease with increasing $\left(\left(\mathrm{T}_{\mathrm{i}}-\mathrm{T}_{\mathrm{a}}\right) / \mathrm{I}\right)$ parameter and the solar radiation increase that lead to maximum efficiency of the collector for minimum reduced temperature.

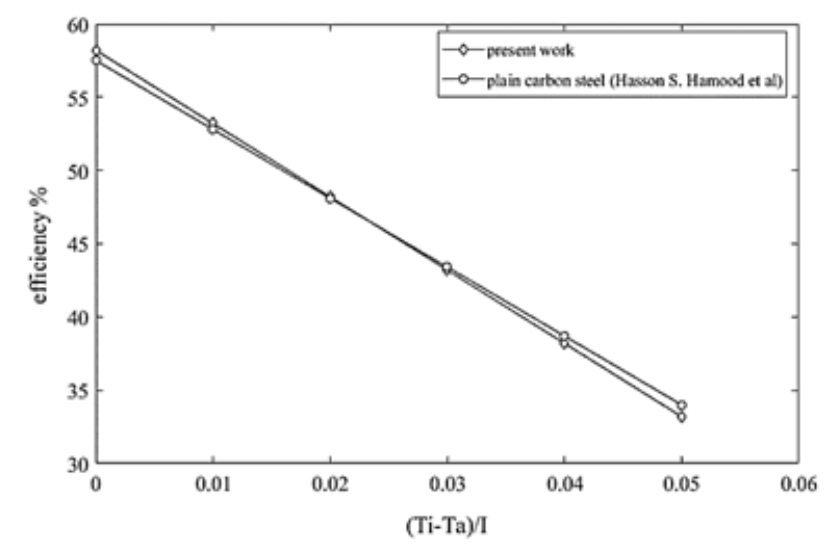

Fig.(5): comparison between present work and previous work

Figure 6 displays the change of the working fluid temperatures with a variation of the solar radiation. It is shown that the fluid temperature is raised with raising solar radiation until 13:00 $\mathrm{pm}$, then, the solar radiation decreases but the fluid temperatures increase more, this due to the remaining heat in the air gap that increases the heat absorbed by working fluid, also the absorbed heat from solar radiation is enough to heat up the water temperature about $\left(20{ }^{\circ} \mathrm{C}\right)$ 


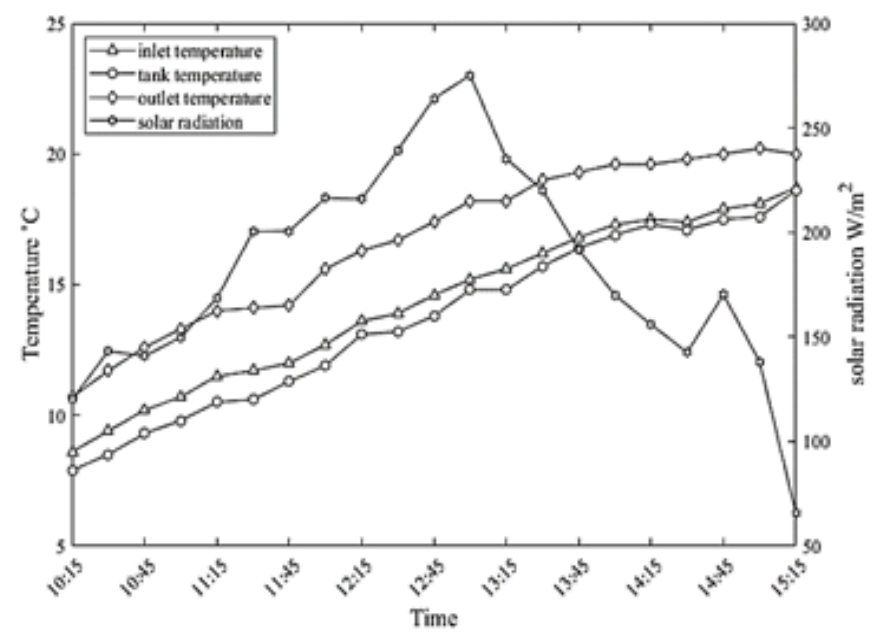

Fig. (6): change in working fluid temperatures with solar radiation variation

The variation of solar collector efficiency is represented in figure 7 . The thermal efficiency of collector increases with the enhancement of the solar radiation till 11:45, then the collector efficiency decreases in spite of increasing the solar radiation till 13:00 afternoon due to the effect of wind speed. It is observed that the maximum efficiency reaches to about $56 \%$ at $11: 45$ and the average collector efficiency is $40.16 \%$.

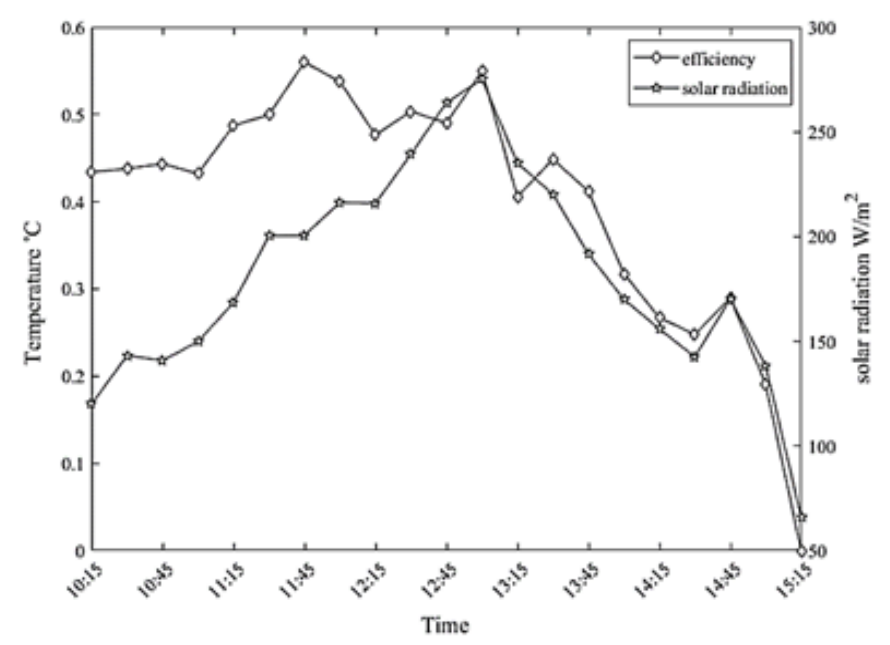

Fig. (7): solar collector efficiency with solar radiation

Figure 8 shows the variation of temperatures at different points of the collector. It is noticed that the absorber temperature is very high and related to the outlet temperature of the water. This phenomenon due to the effect of the contact between the tube and the absorber plate and the thermal conductivity of the absorber plate. The maximum absorber temperature is $67.1{ }^{\circ} \mathrm{C}$ at 13:00 while the maximum temperature of outlet water is at the end of the selected time. The ambient temperature started from $4.3{ }^{\circ} \mathrm{C}$ and reach to the peak value of $12.7{ }^{\circ} \mathrm{C}$ at $13: 00$ o'clock. 


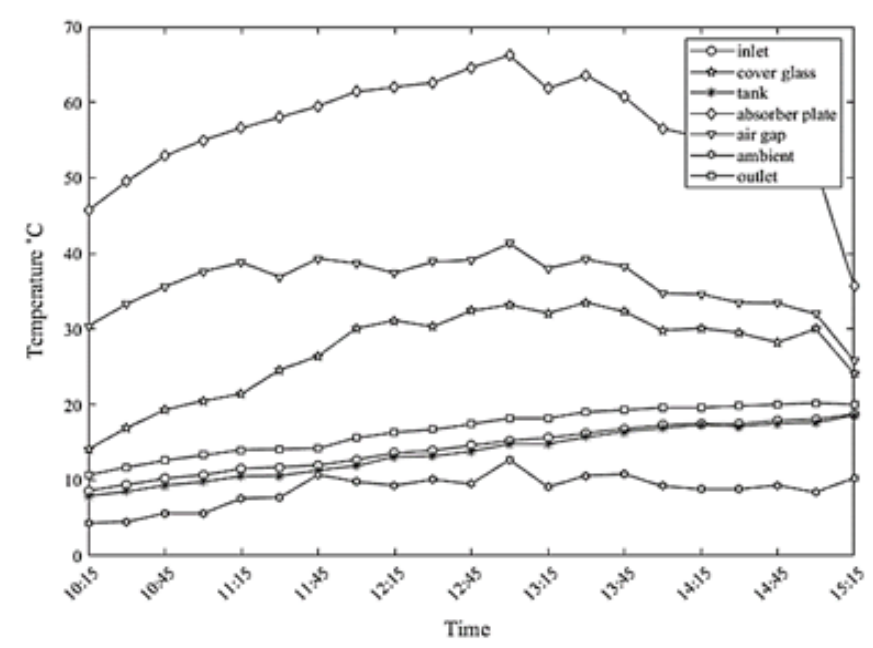

Fig. (8): temperature at different points in the collector

\section{CONCLUSION}

The performance of the flat plate solar collector has been investigated experimentally in Duhok climate. The galvanized steel sheet has been used as an absorber plate because it's available and its price is cheap in Duhok city. The temperatures of all components, wind speed, and solar intensity are measured and collected by the data logger. It is found out that the maximum efficiency of the collector reaches to about $56 \%$. Further, there are other parameters affected on collector efficiency such as wind speed, solar radiation and ambient temperature. However, it is found that the galvanized steel absorber plate is suitable for flat plate solar collector in Duhok climate.

\section{REFERENCES}

Bakari, R., Minja, R. J. A., \& Njau, K. N. (2014). Effect of Glass Thickness on Performance of Flat Plate Solar Collectors for Fruits Drying. Journal of Energy, 14, 1-8.

Dabhane, B. P., \& Adhau, S. P. (2014). Experimental Analysis of Flat Plate Collector Solar Water Heater. International Journal of Science and Engineering Investigations, 3(24), 4-12.

Ekramian, E., Etemad, S. G., \& Haghshenasfard, M. (2014). Numerical Analysis of Heat Transfer Performance of Flat Plate Solar Collectors. Journal of Fluid Flow, Heat and Mass Transfer, 1, 38-42.

Gufta, N. M. N. and J., \& P. (1989). Studies On Gap Spacing Between Absorber And Cover
Glazing In Flat Plate Solar Collectors. International Journal of Energy Research, 13, 727-732.

Hamood, H. S., Salim, B. M., \& Abdulrazzaq, N. M. (2014). Theoratical Analysis Of Flat Plate Solar Collector Placed In Mosul City By Using Different Absorbing Materials And Fluids. Kufa Journal of Engineering, 6(2), 1 12.

Holman, P. J. (2001). Chapter 3: Analysis of experimental data [extract]. In L. Buszek (Ed.), Experimental methods for engineers (pp. 48-60).

Ihaddadene, N., Ihaddadene, R., \& Mahdi, A. (2014). Effect of glazing number on the performance of a solar thermal collector. IREC 2014 - 5th International Renewable Energy Congress, (Et 200), 0-5.

Jalaluddin, J., Arif, E., \& Tarakka, R. (2016). Experimental Study of an SWH System with V-Shaped Plate. Journal of Engineering and Technological Sciences, 48(2), 207-217.

John A. Duffie, W. A. B. (2013). Wiley: Solar Engineering of Thermal Processes, 4th Edition - John A. Duffie, William A. Beckman.

Khadim, I. J., Mahdi, E. J., \& Ubaid, A. H. (2014). Determining Tilt Angle for Fixed Solar Panel Tosites of Iraq's Provinces by Using the Programs on NASA and Google Earth Websites. Engineering \& Technical Journal, 32(3), 3-4.

Khedher, N. Ben. (2018). Experimental Evaluation of a Flat Plate Solar Collector Under Hail City Climate. 8(2), 2750-2754. 
يوخته

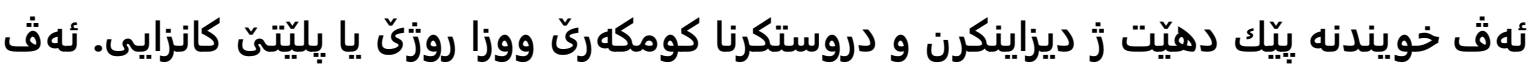

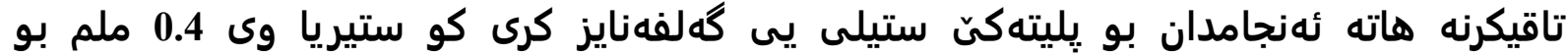

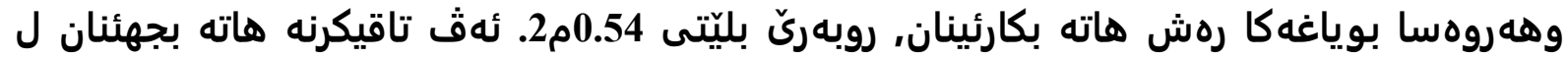

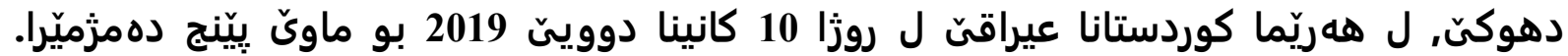

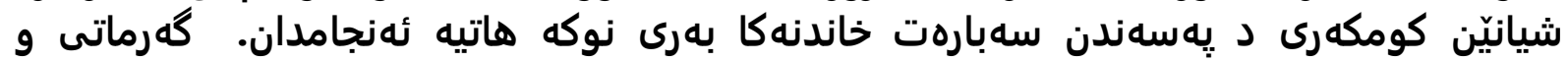

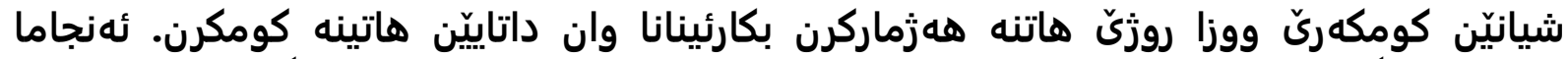

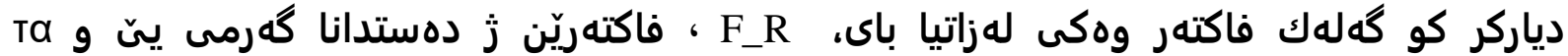

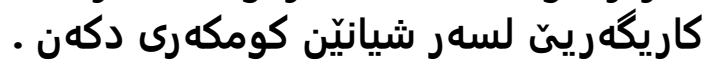

الخلاصة

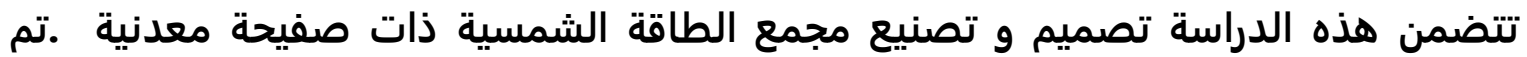

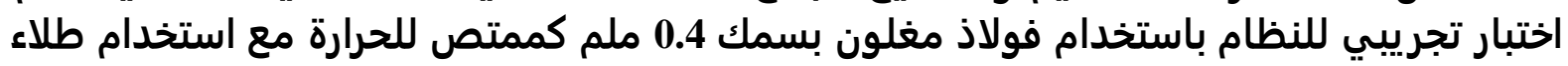

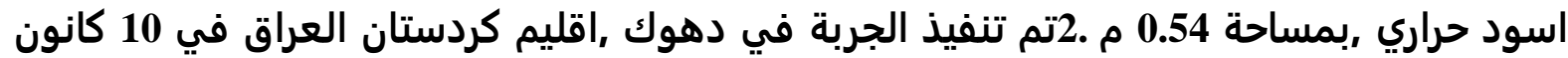

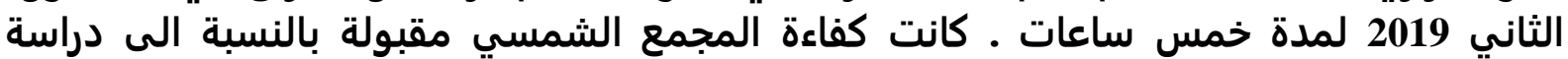

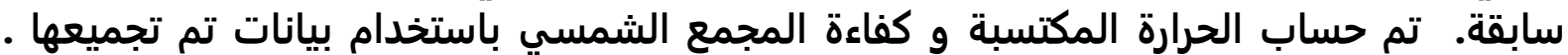

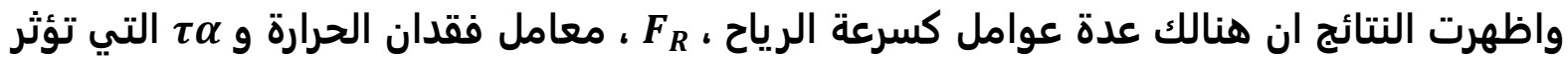
على الكفاءة المجمع • 